\title{
Assessment of paint and swelling following surgical extraction of impacted mandibular third molar using complete and partial wound closure techniques in a tertiary
} institution

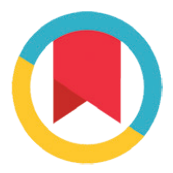

CrossMark

Thomas Owobu, ${ }^{1,2}$ Babatunde O. Bamgbose,,$^{2,3^{*}}$ Abubakar M. Kaura, ${ }^{1,2}$ Ibisola O.

Abstract

Amole, ${ }^{2}$ Junichi Asaumi ${ }^{4}$

Objective: Surgical extraction of impacted mandibular third molars is complicated by pain and swelling. The surgical wound can be closed either partially or completely. This study compared the incidence of postoperative pain and swelling between partial and complete wound closure techniques.

Material and Methods: 120 consenting subjects were randomly allocated into two groups. Group 1 had complete wound closure while group 2 had partial closure. The mean duration of surgery was 3.63 minutes higher in complete wound closure than the partial wound closure technique. The research subjects were evaluated for the degree of pain and swelling at 24 hours, 3rd and 5th days postoperatively using verbal rating scale (VRS) for pain and visual analogue scale (VAS) for swelling. The chi (x2) test was used to determine associations between categorical variables and a $p$-value of 0.05 or less was considered significant in this study. Repeated measures ANOVA was done for pain and swelling.

Results: There were 62 (51.7\%) males and 58 (48.3\%) females; age range was 18 to 45 years and mean age was $31.7 \pm 5.7$. Pain and swelling was maximal on the first postoperative day and this gradually reduced over time. Post hoc tests using Bonferroni correction revealed that wound closure technique elicited a reduction in pain from Day 1 , Day 3 to Day $5(2.92 \pm 0.28,1.18 \pm 0.65$ and $0.34 \pm 0.48$, respectively) which was statistically significant $(p=0.000)$. There was a significant difference in swelling between the two techniques $(p=0.000)$. Conclusion: The wound closure technique elicits a statistically significant reduction in postoperative pain and swelling. The partial third molar wound closure technique provides greater reduction in postoperative pain and swelling.
${ }^{1}$ Department of Dental Surgery, FMC Nguru, Yobe State, Nigeria ${ }^{2}$ Department of Oral and Maxillofacial Surgery, faculty of Dentistry, Bayero University Kano and Aminu Kano Teaching Hospital Kano

${ }^{3}$ Department of Oral Diagnostic Sciences, faculty of Dentistry, Bayero University Kano and Aminu Kano Teaching Hospital Kano

${ }^{4}$ Department of Oral and Maxillofacial Radiology, Okayama University Graduate School of Medicine, Dentistry and Pharmaceutical Sciences

\section{*Corresponding to:}

Babatunde 0. Bamgbose, Department of Oral and Maxillofacial Surgery, faculty of Dentistry, Bayero University Kano and Aminu Kano Teaching Hospital Kano

drtundebamgbose@yahoo.com

Received: 9 January 2019 Revised: 25 February 2019 Accepted: 5 March 2019 Available online 1 April 2019
Keywords: Impaction, Third molar, Wound closure, Pain, Swelling, Mouth opening

Cite this Article: Owobu T, Bamgbose OB, Kaura AM, Amole 10, Asaumi J. 2019. Assessment of paint and swelling following surgical extraction of impacted mandibular third molar using complete and partial wound closure techniques in a tertiary institution. Journal of Dentomaxillofacial Science 4(1): 15-21. D0l: 10.15562/jdmfs.v4i1.855

\section{Introduction}

The mandibular third molar is the last tooth to erupt in an adult human dentition. ${ }^{1}$ It erupts between the ages of 17 and 25 year but the eruption dates may, however, vary with race. ${ }^{1,2}$ The mandibular third molar may erupt as early as 14 years in Nigerians, but up to 26 years in Europeans. ${ }^{3,4}$ Several studies also suggest that the average age for the eruption of mandibular third molar in males is approximately 3-6 months ahead of females. ${ }^{5,6}$

During mandibular third molar development and eruption, it usually undergoes continuous positional and anatomical changes which in some cases may result in partial or complete submersion or impaction of teeth..$^{1-7}$ The process of mandibular third molar development is thought to be influenced by local and systemic factors, race, nature of diet, the intensity of the use of the masticatory apparatus and possibly genetic background. ${ }^{6}$

The term 'impaction' is of Latin origin coming from the term "Impactus." It is generally used to describe an organ or structure which has been prevented from assuming its normal position because of structural and mechanical obstruction. ${ }^{7}$

Clinically and radiologically, there are two types of impactions, namely complete and partial impactions. Complete impaction refers to a clinical state where the tooth is covered by bone and mucosa and is prevented from erupting into a normal functional position; whereas, partial impaction means that the tooth is partially visible or in communication with the oral cavity and has failed to erupt fully into a normal anatomical position. ${ }^{8}$ Not all cases of impacted mandibular third molars present with symptoms, but a considerable number usually present at the dental clinic and may require surgical extraction. ${ }^{8-10}$ This makes surgical extractions of impacted mandibular third molars one of the most frequently performed procedures in oral surgery clinic. This surgical intervention involves traumatic injury to adjacent soft and bony tissues with resultant postoperative complications; such as pain, swelling and limitation of mouth opening. ${ }^{8}$ Studies have shown that the degree of the postoperative pain varies and it can significantly influence patient's quality of life (QoL), mainly during the first three postoperative days. ${ }^{10}$ The immediate postoperative pain and swelling is as a result of inflammatory response secondary to trauma. ${ }^{11}$ The intensity of this trauma-induced inflammatory response has been attributed to factors such as; as age of the patient, gender, degree of impaction and wound closure - 
technique used after extraction. After a third molar surgery, the wound can either be left alone (without suturing), closed partially or closed completely as the case may require. ${ }^{12}$ Though some authors advocated a suture-less tecnique, ${ }^{12}$ this is not a practice in our clinics as no surgeon feels comfortable leaving extraction socket of surgically extracted mandibular third molar open without a single sutire. For the partial wound closure technique, one or two interrupted sutures are applied to reposition the mucoperiosteal flap but the socket still communicating with the oral cavity. ${ }^{11}$ Findings from the literature show that a partially closed socket allows free drainage of inflammatory exudate thereby reducing postoperative pain and swelling. the draw back with this technique is that it allows accumulation of food debris which may infect the wound thus affecting patient's QoL. this has made some authors to consider an alternative between partial and complete wound closure techniques that would reduce immediate postoperative pain and swelling as well as to improve the QoL of the patient after the surgery. The aim of this study was to compare the incidence of postoperative pain and swelling between partial and complete wound closure techniques after ssurgical extraction of impacted mandibular third molars.

\section{Material and Methods}

This was a randomized, double-blinded, prospective study of pain and swelling following mandibular third molar disimpaction using complete and partial wound closure techniques over a period of 12 months. It was conducted amongst consenting patients between the ages of 18 and 45 years that presented in our oral surgery and dental retainership clinics for surgical extraction of impacted mandibular third molars. Patients with bleeding disorder, facial cellulitis, women who were breast feeding and patients who were receiving treatment with analgesic, anti-inflammatory treatment (both steroidal (SAIDS) and non-steroidal anti-inflammatory, were excluded from the study.

Ethical approval was obtained from the Aminu Kano Teaching Hospital Ethical Review Committee.

The surgical removal was carried out in the Oral Surgery Clinic of Aminu Kano Teaching Hospital (AKTH), Kano. Patients whose impactions have been confirmed and met the inclusion criteria were randomly allocated by balloting into two groups: group I (complete closure) and group II (partial closure). In Group I (partial wound closure) the flap was repositioned and sutured with one or two stitches (silk, 3-0) with the soft and hard tissues still maintaining their anatomical configuration.

In group 1I (complete wound closure) the socket was completely closed by rotating the mesial mucoperiosteal flap and sutured over the socket to the mucoperiostium on the lingual side to cover the extraction socket. The mean duration of surgery, from incision to completion of the suture was recorded in minutes.

All study participants received postoperative instructions and were placed on medications (amoxicillin, 500mg 8 hourly for 5 days, metronidazole 400mg 8 hourly for 5 days and diclofenac sodium 50mg 12 hourly for 3 days) to prevent possible wound infections and control pain.

A total of 120 patients were studied in both groups and the sample size was calculated using from the formula for comparing two means.

Data collection was obtained with the aid of a questionnaire. Information collected included subject's demographics, pattern of impaction, reasons for surgical extraction and post-operative measurement for pain and swelling. The recording was done by the primary investigator with the help of a trained assistant.

\section{Results}

A total of 120 subjects, ages 18 to 45 years, who met the inclusion criteria and consented, were recruited into the study. Mean age of the participants was 31.7 \pm 5.7 . There were $51.7 \%(n=62)$ males and $48.3 \%(n=58)$ females. The subjects were made up of students $38.3 \%(n=46)$, civil servants $33.4 \%$ $(n=40)$, house wives $15.0 \%(n=18)$ and business/ traders $13.3 \%(n=16)$. Hausa and fulani ethnic groups were equally represented in the study with $51(42.5 \%)$ and $48(40.0 \%)$ respectively. Mesioangular impaction was the most common type of impaction in this study $70.0 \%(\mathrm{n}=84)$ followed by distoangular $12.6 \%(n=15)$, horizontal and vertical $8.3 \%(n=10)$ impactions. Table 1 there was no equitable distribution of the participants in terms of indications for third molar removal. Pericoronitis cases were 55.8 $\%(n=68)$, caries $36.7 \%(n=44)$. The mean duration of surgery was longer in the complete wound closure group (32.7 \pm 5.62$)$, while mean duration of partial wound closure technique was $29.07 \pm 4.27$.

The chi-square test for independence in relation to the two techniques indicated that postoperative pain at day 1 was $2.95 \pm 0.22$ and $2.88 \pm 0.32$ respectively in groups 1 and 2 while swelling was $4.87 \pm 034$ in group 1 and $4.83 \pm 0.38$ in group 2 . 
Table 2 mean pain score was significantly higher in group 1 compared to group $2(\mathrm{p}=0.048)$. At day 3 , the mean pain score was $1.20 \pm 0.063$ in group 1 and $1.18 \pm 0.65$ in group 2 , while swelling was $2.47 \pm 0.62$ in group 1 and $1.90 \pm 0.66$ in group 2 . The difference between the groups was statistically significant for swelling $(\mathrm{p}=0.001)$ but not for pain $(\mathrm{p}=0.864)$. At day 5 , the mean pain score was $0.38 \pm 0.49$ in group 1 and $0.65 \pm 0.76$ in group 2 , while swelling was $0.75 \pm 0.47$ in group 1 and $0.18 \pm 0.39$ in group 2 . The difference between the groups was statistically significant for swelling $(\mathrm{p}=0.001)$ but not for pain $(\mathrm{p}=0.564)$. Table 2.

A repeated measures ANOVA with a greenhouse-geisser correction determined mean scores for pain differed statistically significantly between time points $(p=0.006)$. Post hoc tests using bonferroni correction revealed that wound closure technique elicited a reduction in pain from Day 1 , Day 3 to Day $5(2.92 \pm 0.28,1.18 \pm 0.65$ and $0.34 \pm 0.48$, respectively) which was statistically significant $(\mathrm{p}=0.000)$. Therefore, we can conclude that wound closure technique elicits a statistically significant reduction in postoperative pain from immediate postoperative period to Day 5 tables 3-5. Table 3 indicates that postoperative swelling was maximal at 24 hours following surgery, mean $=$ 4.84. Using an ANOVA with repeated measures with a greenhouse-geisser correction, the mean scores for swelling were statistically significantly different $(\mathrm{p}=0.000)$. Table 4 shows an overall significant difference in mean for swelling, but we do not know where the differences occurred. The pairwise comparison allows us to discover which specific means differed. Table 5 gives us the significant level for differences between the individual time points. Post hoc test using the Bonferroni correction revealed that wound closure technique elicited a reduction in swelling from day 1 , day 3 to day $5(4.84 \pm 0.37,2.18 \pm 0.70$ and $0.46 \pm 0.50$, respectively) which was statistically significant $(\mathrm{p}=0.000)$. Wound closure technique appears to elicit a reduction in postoperative swelling from day 1 to day 5 .

On table 6, the column labelled " $R$ " shows the value of the multiple correlation between the predictors and the outcome (pain). The correlation between pain and the predictors is 0.317 . The value of $\mathrm{R} 2$ is 0.100 , which means that the predictors account for $10 \%$ of the variation in pain. The adjusted R2 gives us some idea of how well our model generalizes. The difference for our model is $(0.100-0.035=0.065$ or $6.5 \%)$. This shrinkage means that if the model were derived from the population rather than a sample, it would account for approximately $6.5 \%$ less variance in the outcome.
The correlation between swelling and predictors is 0.513 table 6 . The value of $\mathrm{R} 2$ is $0.264(26.4 \%)$. The adjusted R2 and R difference for our model is (0.513-0.264 $=0.249$ or $24.9 \%)$. If the model were derived from the population rather than a sample, it would account for approximately $24.9 \%$ less variance in the outcome. Table 7 test whether the model is significantly better at predicting the outcome than using the mean as a "best guess." The F-ratio represents the ratio of the improvement in prediction that results from fitting the model ("Regression"), relative to the inaccuracy that still exists in the model ("Residual"). If the improvement due to fitting the regression model is much greater than the inaccuracy within the model, then the value of $F$ will be greater than 1. For our model of predictors and pain, the F-ratio is 0.149 which is very unlikely to have happened by chance $(p<0.05)$. The predictors, including wound closure technique, are not responsible for the improvement in postoperative pain. For our model of predictor and swelling, the F-ratio is 4.968 table 7 which is very unlikely to have happened by chance $(p<0.05)$. The predictors, including wound closure technique, are responsible for the improvement in postoperative swelling.

In multiple regression table 8 , the model takes the form of an equation that contains a coefficient (b) for each predictor. The estimates of these values indicate the individual contributions of each predictor to the model. If the value is positive, we can tell that there is a positive relationship between the predictor and the outcome; whereas a negative coefficient represents a negative relationship. If the $t$-test associated with a b-value is significant (if the value in the column labelled Sig. is less than $0.05)$ then that predictor is making a significant contribution to the model. The smaller the value of Sig., the greater the contribution of that predictor. For our model, wound closure technique, $\mathrm{t}=-0.939(\mathrm{p}<0.05)$. On Table 8, for our model on postoperative swelling, wound closure technique, $\mathrm{t}=-0.461(\mathrm{p}<0.05)$.

\section{Discussion}

The extent of postoperative pain and swelling are indicators of patient comfort during the first five postoperative days following third molar surgery. Pain is a subjective experience and is influenced by patient's age, cultural background, educational level, previous experience of pain, pain threshold and tolerance. ${ }^{13}$ In our study, the intensity of pain was highest on immediate postoperative day and 
Table 1 Social demographic and preoperative characteristics of patients. $(\mathrm{N}=120)$

\begin{tabular}{llllc}
\hline & & $\begin{array}{l}\text { Complete closure } \\
\text { X2 (SD) }\end{array}$ & $\begin{array}{l}\text { Partial closure } \\
\text { X2 (SD) }\end{array}$ & p-value \\
\hline \multirow{2}{*}{ Pain } & Day 1 & $2.95(0.22)$ & $2.88(0.32)$ & 0.048 \\
& Day 3 & $1.20(0.63)$ & $1.18(0.65)$ & 0.864 \\
& Day 5 & $0.38(0.49)$ & $0.65(0.76)$ & 0.564 \\
Swelling & Day 1 & $4.87(0.34)$ & $4.83(0.38)$ & 0.453 \\
& Day 3 & $2.47(0.62)$ & $1.90(0.66)$ & 0.001 \\
& Day 5 & $0.75(0.47)$ & $0.18(0.39)$ & 0.001 \\
\hline
\end{tabular}

Table 2 Chi-square test for independence of postoperative pain and swelling in relation to complete and primary wound closure

\begin{tabular}{|c|c|c|c|}
\hline \multicolumn{2}{|c|}{ Description of social demographic } & \multirow{2}{*}{$\begin{array}{l}\text { Complete closure } \\
\mathbf{n}(\%)\end{array}$} & \multirow{2}{*}{$\begin{array}{l}\text { Partial closure } \\
\text { n(\%) } \\
9(15.0)\end{array}$} \\
\hline Age & $18-25$ & & \\
\hline & $26-35$ & $36(60.00)$ & $36(60.00)$ \\
\hline & 36 and above & $16(26.7)$ & $15(25.0)$ \\
\hline \multirow[t]{2}{*}{ Gender } & Male & $33(55.0)$ & $29(48.0)$ \\
\hline & Female & $27(45.0)$ & $31(52.0)$ \\
\hline \multirow[t]{4}{*}{ Occupation } & Civil Servant & $18(30.0)$ & $22(36.7)$ \\
\hline & House wives & $8(13.3)$ & $22(36.7)$ \\
\hline & Students & $25(41.7)$ & $21(35.0)$ \\
\hline & Business/Traders & $9(15.0)$ & $7(11.7)$ \\
\hline \multirow[t]{5}{*}{ Tribe } & Ibo & $6(10.0)$ & $5(8.3)$ \\
\hline & Yoruba & $4(6.7)$ & $3(5.0)$ \\
\hline & Hausa & $25(41.7)$ & $27(45.0)$ \\
\hline & Fulani & $24(40.0)$ & $25(41.7)$ \\
\hline & Others & $1(1.6)$ & $0(0)$ \\
\hline Educational & Quaranic & $12(20.0)$ & $14(23.3)$ \\
\hline \multirow[t]{4}{*}{ Qualification } & Primary & $2(3.3)$ & $3(5.0)$ \\
\hline & Secondary & $4(6.7)$ & $6(10.0)$ \\
\hline & Polytechnic & $5(8.3)$ & $3(5.0)$ \\
\hline & University & $37(61.7)$ & $34(56.7)$ \\
\hline \multicolumn{2}{|c|}{$\begin{array}{l}\text { Description of preoperative } \\
\text { characteristics }\end{array}$} & $\begin{array}{l}\text { Complete closure } \\
\text { Mean } \pm \text { (SD) }\end{array}$ & $\begin{array}{l}\text { Partial closure } \\
\text { Mean } \pm \text { (SD) }\end{array}$ \\
\hline \multirow{6}{*}{$\begin{array}{l}\text { Quadrant Location } \\
\text { of Tooth } \\
\text { Type of Impaction }\end{array}$} & Mandibular Right & $35(58.30)$ & $32(53.30)$ \\
\hline & Mandibular Left & $25(41.70)$ & $28(46.70)$ \\
\hline & Mesioangular & $41(68.4)$ & $39(65.0)$ \\
\hline & Distoangular & $9(15.0)$ & $10(16.7)$ \\
\hline & Horizontal & $5(8.3)$ & $6(10.0)$ \\
\hline & Vertical & $5(8.3)$ & $5(8.3)$ \\
\hline \multirow{3}{*}{$\begin{array}{l}\text { Indication for } \\
\text { extraction }\end{array}$} & Pericoronitis & $35(58.3)$ & $32(53.3)$ \\
\hline & Dental caries & $19(31.7)$ & $25(41.7)$ \\
\hline & Prophylaxis & $6(10.0)$ & $3(5.0)$ \\
\hline
\end{tabular}

decreased gradually over five days. This pattern of the present study observed that a significant increase in the intensity of postoperative pain was recorded among study participants older than 37 years of age. Our study evaluated postoperative swelling using visual analogue scale (VAS), which is considered to be an efficient tool to evaluate clinical parameters influenced by the subjective experience of an individual. ${ }^{15,20}$
The VAS scale is a reliable and repeatable method when compared with three-dimensional mechanical measurement of swelling using an extraoral cephalostat.

Photographic techniques and computed tomography have also been proposed for measurement of anatomical changes in the profile of patients following third molar surgery. ${ }^{22}$ The benefit of exposing patients to radiation through CT scanning for measurement of postoperative swelling has to be weighed against the corresponding radiation exposure. Another method of evaluating postoperative swelling was proposed by Bjorn et al..$^{23}$ This technique is sophisticated but complex and involves the use stereophotographic techniques.

Our study agrees with conclusions of other authors who carried out comparative studies on wound closure techniques that allow for drainage (partial closure, open healing, secondary closure) and those that restrict drainage (primary closure, total closure, primary healing) in third molar surgery. ${ }^{12,20,24-33}$ The findings of our study show that both partial and complete closure produce similar outcome of less postoperative morbidity in terms of pain and swelling. However, the wound closure technique elicits a statistically significant reduction in postoperative pain and swelling. The partial third molar wound closure technique provides greater reduction in postoperative pain and swelling. The multiple correlation and modeling methods used in our study enabled to predict the interactions of wound closure technique, tribe, tooth location, age, type of impaction and duration of surgery with pain and swelling. In agreement with other authors, this study did not find a statistically significant correlation between patient's ethnicity and the intensity of postoperative swelling and pain. ${ }^{34-36}$

Some authors believe that partial wound closure allows drainage of inflammatory exudates, thereby eliminating the need for steroid administration and use of ice packs. ${ }^{20,33}$ When compared with complete wound closure technique, partial wound closure is less traumatic. The disadvantage of partial wound closure technique is that healing may be delayed due to drainage of inflammatory exudates ${ }^{32,33}$ and there is also the possibility of formation of periodontal

Table 3 Descriptive statistic for postoperative pain and swelling in both techniques. $(n=120)$

\begin{tabular}{lcccccc}
\hline & \multicolumn{2}{c}{ Day 1 } & \multicolumn{2}{c}{ Day 3 } & \multicolumn{2}{c}{ Day 5 } \\
& Mean & (SD) & Mean & (SD) & Mean & (SD) \\
\hline Pain & 2.92 & $(0.279)$ & 1.18 & $(0.646)$ & 0.34 & $(0.477)$ \\
Swelling & 4.84 & $(0.367)$ & 2.18 & $(0.698)$ & 0.46 & $(0.500)$
\end{tabular}


Table 4 Multivariate repeated measure analysis of variance for day's pain in relation to two techniques

\begin{tabular}{|c|c|c|c|c|c|c|c|}
\hline & \multirow[b]{2}{*}{ Mauchly's W } & \multirow{2}{*}{$\begin{array}{l}\text { Approx } \\
\text { Chi-Square }\end{array}$} & \multirow[b]{2}{*}{ Df } & \multirow[b]{2}{*}{ Sig. } & \multicolumn{2}{|c|}{ Epsilon $^{\text {b }}$} & \multirow[b]{2}{*}{ Lower-bound } \\
\hline & & & & & Greenhouse-Geisser & Huynh-Feldt & \\
\hline Pain & 0.915 & 10.351 & 2 & 0.006 & 0.922 & 0.936 & 0.500 \\
\hline Swelling & 0.839 & 20.679 & 2 & 0.000 & 0.862 & 0.873 & 0.500 \\
\hline
\end{tabular}

Table 5 Pairwise comparisons for postoperative pain and swelling

\begin{tabular}{|c|c|c|c|c|c|c|}
\hline (I) pain & (J) pain & Mean Difference (I-J) & Std Error & Sig. $^{b}$ & $\begin{array}{l}95 \% \mathrm{Cl} \\
\text { Lower Bound }\end{array}$ & Upper bound \\
\hline \multirow[t]{2}{*}{1} & 3 & $1.739^{*}$ & 0.065 & 0.000 & 1.611 & 1.868 \\
\hline & 5 & $2.751^{*}$ & 0.050 & 0.000 & 2.472 & 2.670 \\
\hline \multirow[t]{2}{*}{3} & 1 & $-1.739^{*}$ & 0.065 & 0.000 & -1.868 & -1.611 \\
\hline & 5 & $0.832^{*}$ & 0.061 & 0.000 & 0.711 & 0.953 \\
\hline \multirow[t]{2}{*}{5} & 1 & $-2.571^{\star}$ & 0.050 & 0.000 & -2.670 & -2.472 \\
\hline & 3 & $-0.832^{*}$ & 0.061 & 0.000 & -0.953 & -0.711 \\
\hline (I) Swelling & (J) Swelling & & & & & \\
\hline \multirow[t]{2}{*}{1} & 3 & $2.658^{*}$ & 0.066 & 0.000 & 2.527 & 2.790 \\
\hline & 5 & $4.383^{*}$ & 0.052 & 0.000 & 4.281 & 4.486 \\
\hline \multirow[t]{2}{*}{3} & 1 & $-2.658^{\star}$ & 0.066 & 0.000 & -2.790 & -2.527 \\
\hline & 5 & $1.725^{\star}$ & 0.049 & 0.000 & 1.628 & 1.822 \\
\hline \multirow[t]{2}{*}{5} & 1 & $-4.383^{*}$ & 0.052 & 0.000 & -4.486 & -4.281 \\
\hline & 3 & $-1.725^{\star}$ & 0.049 & 0.000 & -1.822 & -1.628 \\
\hline
\end{tabular}

95\% CI: 95\% confidence interval for difference

Table 6 Model Summary for postoperative pain and swelling

\begin{tabular}{|c|c|c|c|c|c|c|c|c|c|c|}
\hline & \multirow[b]{2}{*}{ Model } & \multirow[b]{2}{*}{$\mathbf{R}$} & \multirow[b]{2}{*}{$\mathbf{R 2}$} & \multirow[b]{2}{*}{ Adjusted R2 } & \multirow[b]{2}{*}{$\begin{array}{l}\text { Std. Error of the } \\
\text { Estimate }\end{array}$} & \multicolumn{4}{|c|}{ Change Statistics } & \multirow[b]{2}{*}{ Sig. F Chang } \\
\hline & & & & & & R2 Change & F Change & dfl & df2 & \\
\hline Pain & 1 & $0.317 \mathrm{a}$ & 0.100 & 0.035 & 0.94197 & 0.100 & 1.546 & 8 & 111 & 0.149 \\
\hline Swelling & 1 & $0.513 \mathrm{a}$ & 0.264 & 0.211 & 1.08043 & 0.264 & 4.968 & 8 & 111 & 0.000 \\
\hline
\end{tabular}

a. Predictors (constant): reason for extraction, wound closure technique, tribe, tooth location, age, type of impaction, time, gender

Table 7 Multiple regression for postoperative pain and swelling

\begin{tabular}{|c|c|c|c|c|c|c|}
\hline & Model & Sum of Squares & Df & Mean Square & $\mathbf{F}$ & Sig. \\
\hline \multirow[t]{3}{*}{ Pain } & 1 Regression & 10.975 & 8 & 1.372 & 1.546 & ${ }^{\star} 0.149 \mathrm{~b}$ \\
\hline & Residual & 98.492 & 111 & 0.887 & & \\
\hline & Total & 109.467 & 119 & & & \\
\hline \multirow[t]{3}{*}{ Swelling } & 1 Regression & 46.393 & 8 & 5.799 & 4.968 & ${ }^{* *} 0.000 \mathrm{~b}$ \\
\hline & Residual & 129.573 & 111 & 1.167 & & \\
\hline & Total & 175.967 & 119 & & & \\
\hline
\end{tabular}

a. Dependent variables: pains and swelling

b. Predictors (constant): reason for extraction, wound closure technique, tribe,

Tooth location, age, type of impaction, time, gender

*No statistical significance existed between the two groups for pain

** Statistical significance existed between the two groups for swelling 
Table 8 Model Parameters for postoperative pain and swelling

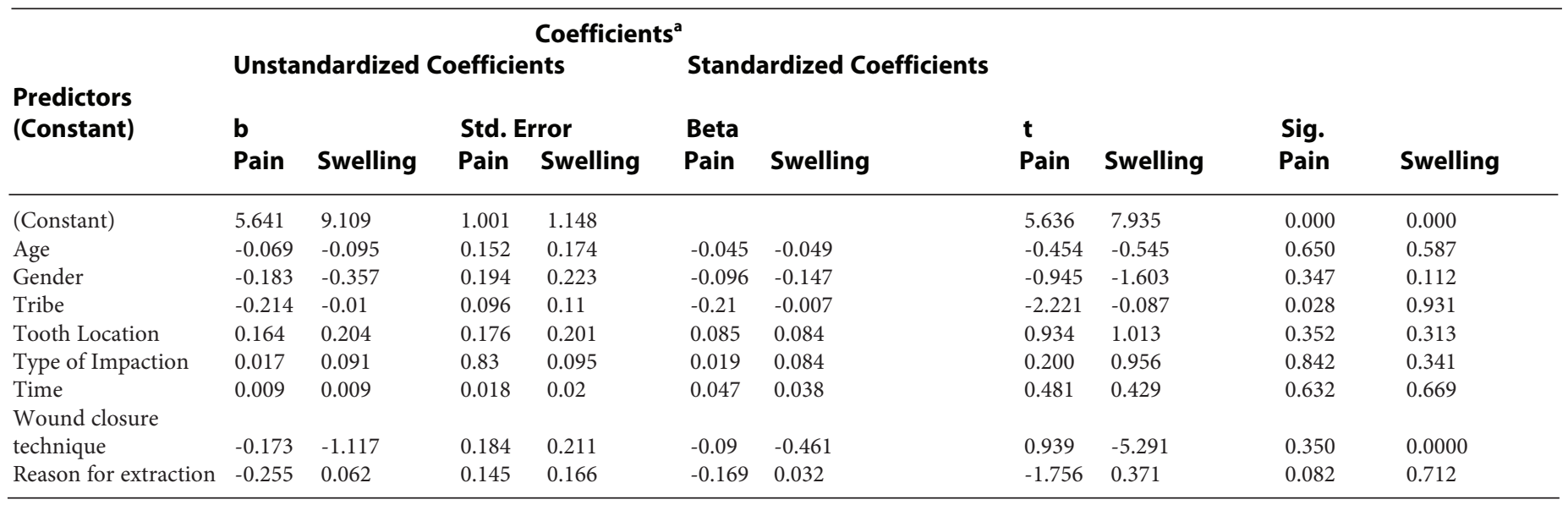

a. Dependent Variable: pain and swelling

pockets in relation to the adjacent second molar. In addition, there is direct communication between the extraction socket and the oral cavity. Therefore, food debris can lodge in the socket. ${ }^{32,33}$ The present study differs from those of Suddhasthira et al. ${ }^{33}$ Who did not find any significant difference between primary and secondary closure techniques with respect to postoperative pain and swelling. The findings of our study with particular reference to postoperative pain also differ from those of Rakprasitkul and Pairuchvej. ${ }^{25}$ Who found no difference in postoperative pain in patients with tube drain and controls.

Majority of the participants in the present study were in the third decade of life and had University education. The educational level enabled understanding and compliance with postoperative instructions and request for follow-up. The Hausa/ Fulani ethnic groups were majorly represented in the study because the study was carried out in the Northern part of the country. Mesioangular impaction was the most common type of impaction in our study. This is in agreement with similar studies. ${ }^{3,9,11,12,16}$ The most frequent indication for extraction of the mandibular third molar in our study was pericoronitis.

\section{Conclusion}

The wound closure technique elicits a statistically significant reduction in postoperative pain and swelling. The partial third molar wound closure technique provides greater reduction in postoperative pain and swelling.

\section{Acknowledgment}

The authors appreciate the kind assistance of the following individuals during this research work: Dr.(Mrs) T.G.Amole, Dr J. Adeoye, Dr B. Fakuade and Abdullahi Alhassan.

\section{Conflict of Interest}

The manuscript has been read and approved by all the authors and the requirements for authorship, as stated on the journal website, have been met and each author believed that the manuscript represents honest work. The authors declared no conflicts of interest in this study.

\section{References}

1. Major M, Saunders W, Nelson B, Stanley J. Wheeler's dental anatomy, physiology, and occlusion. 2003;32,45-53.

2. Thesleff I, Vahtokari A, Partanen AM. "Regulation of organogenesis. Common molecular mechanisms regulating the development of teeth and other organs". Int J Developmental Biolo1995;39: 35-50.

3. Odusanya SA, Abayomi IO. Third molar eruption among rural Nigerians. Oral Surg Oral Med Oral Pathol 1991;97: 151-154.

4. Agarwal KN, Gupta R, Faridi MM, et al. Permanent dentition in Delhi boys of age 5-15 years. Indian J Peadiatrics 2004;41: 1031-1035.

5. Khan NB, Chohan AN, AlMograbi B, et al. Eruption time of permanent first molar and incisors among a sample of Saudi male school children. Saudi Dent J 2006;18: 18-24.

6. Kruger E, Thomson WM, Konthasing P. Third molar outcomes from age 18 to 26 years: findings from a population-based New Zealand longitudinal study. Oral Surg Oral Med Oral Pathol Oral Radiol Endod 2001;92: 150-155. 
7. Peterson LJ. Impacted teeth. In: Principles of Oral and Maxillofacial Surgery, Vol 1 5th ed. Philadelphia, London, Toronto: WB Saunders Co; 2004. p. 250-311.

8. Peterson LJ. Principles of Management of Impacted Teeth. 3rd ed. St. Louis: Mosby; 1998. p. 215-248.

9. Adeyemo WL, James O, Ogunlewe MO, et al. Indications for extractions of third molars: a review of 1763 cases. Niger. Postgrad Med J 2006;15: 42-45.

10. Adeyemo WL, Ogunlewe MO, Ladeinde AL, et . Prevalence and surgical morbidity of impacted mandibular third molar removal in the aging population: a retrospective study at the Lagos University Teaching Hospital. Afr J Med Sci 2006;35:479-83.

11. Adeyemo WL, Bamgbose BO, Obi EV, et al. Effect of age, impaction types and operative time on inflammatory tissue reactions following lower third molar surgery. Head Face Med. 2011 Apr 28;7:8-11.

12. Osunde OD, Adebola RA, Saheeb BD. A comparative study of the effect of suture-less and multiple suture techniques on inflammatory complications following third molar surgery. Int J Oral \& Maxillofac Surg 2012;41: 1275-1279.

13. Amen MM, Laskin DM. Prophylactic use of indomethacin for prevention of postsurgical complications after removal of impacted third molars. Oral Surg 1983;55: 448-551.

14. Tiwana PS, Foy SP, Shugars DA, et al. The impact of intravenous corticosteroid with third molar surgery in patients at high risk for delayed health-related quality of life and clinical recovery. J Oral Maxillofac Surg 2005;63: 55-62.

15. Ruta, D.A., Bissias, E, Ogston, S. Assessing health outcomes after extraction of third molars. The postoperative symptom severity (PoSSe) Scale. British J Oral Maxillofac Surg 2000;38: 480-487.

16. Gbotolorun OM, Arotiba GT, Ladeinde AL. Assessment of factors associated with surgical difficulty in impacted mandibular third molar extraction. J Oral Maxillofac Surg 2007;65: 1977-1983.

17. Blondeau F, Daniel NG. Extraction of impacted mandibular third molars: postoperative complications and their risk factors. J Can Dent Assoc 2007;73: 325-332.

18. Akinwande JA. Mandibular third molar impaction a comparison of two methods for predicting surgical difficulty. Nig Dent J 1991;10: 3-7.

19. Akadiri OA, Obiechina AE. Assessment of difficulty in third molar surgery a systematic review. J Oral Maxillofac Surg 2009;67: 771-774.

20. Saheeb BD, Obuekwe ON. An audit of mandibular third molar surgery. Nig J Surg Res 2001;3: 66-74.

21. Archer WH. Oral and Maxillofacial Surgery. 5th ed. Philadelphia: WB Sounders Co; 1975. p. 321-335.

22. Victoria AM. Relation of patient and surgical extraction of third molars. Med Oral 2002;7: 360-369.

23. Ong KS, Seymour RA. Pain measurement in humans. Surg-J R Coll Surg E 2004;2: 15-27.
24. Anighoro EO, Gbotolorun OM, Adewole RA, et al. Assessment of the effect of wound closure technique on postoperative sequelae and complications after impacted mandibular third molar extraction. J Stomatolog 2003;3: 527-532.

25. Jabber JK. A comparison between primary and secondary wound closure after surgical removal of lower third molars according to pain and swelling. Natl J Maxillofac Surg 2008;8: 233-241.

26. Kira K, Harish S, Uma M. Primary and secondary closure of the surgical wound after removal of impacted mandibular third molars. Br J Oral Maxillofac Surg 2011;10: 112-117.

27. Dubois DD, Pizer ME, Chinnis RJ. Comparison of primary and secondary closure techniques after removal of impacted mandibular third molars. J Oral Maxillofac Surg 1982;40: 631-634.

28. McGrath C, Comfort MB, Lo EC, et al. Changes in quality of life following third molar surgery the immediate postoperative period. Br Dent J 2003;194: 265-268.

29. Pippi R, Perfetti G. Lingual displacement of an entire lower third molar. Report of a case with suggestions for prevention and management. Minerva Stomatol 2002;51: 263-268.

30. Pederson A. Inter-relationship of complaints after removal of impacted third molars. Int J Oral Maxillofac Surg 1985;14: 241-247.

31. Almendros-Marqués N, Berini-Aytés L, Gay-Escoda C. Evaluation of intraexaminer and interexaminer agreement on classifying lower third molars according to the systems of Pell and Gregory and of Winter. J Oral Maxillofac Surg 2008;66: 893-899.

32. García GA, Gude SF, Gallas TM, et al. Trismus and pain after removal of a lower third molar. Effects of raising a mucoperiosteal flap. Med Oral 2001;6: 391-396.

33. Suddhasthira T, Chaiwat S. Sattapongsda P. A comparative study of primary and secondary closure techniques after removal of impacted mandibular third molars. Thai J Oral Maxillofac Surg 1991;5: 67-77.

34. Grossi GB, Maiorana C, Garramone RA, et al. Assessing postoperative discomfort after third molar surgery: a prospective study. J Oral Maxillofac Surg 2007;65: 901-905.

35. Al-Khateeb T, Alnahar A. Pain experience after simple tooth extraction. J Oral Maxillofac Surg 2008;66: 911-913.

36. Sato F, Ricardo L, Sprino L, et al. Short-term outcome of postoperative patient recovery perception after surgical removal of third molars. J Oral Maxillofac Surg 2009;67: 1090-1091.

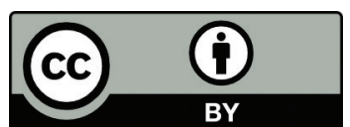

This work is licensed under a Creative Commons Attribution 

